\title{
El esquema argumentativo de Toulmin como herramienta de control de racionalidad de las decisiones judiciales ${ }^{1}$
}

\section{Toulmin's argumentative scheme as a tool for controlling the rationality of judicial decisions}

\author{
Andrés Fernando Mejía Restrepo \\ Candidato a doctor en Derecho Procesal \\ Magíster en Derecho Procesal \\ Correo electrónico: amejia3@areandina.edu.co
}

\section{Resumen}

Inicialmente se relaciona, en este artículo, el concepto de argumentación jurídica, así como su finalidad. A continuación, se refiere la teoría de Stephen Toulmin y un esquema fundamentado en sus planteamientos, aplicable al análisis de providencias judiciales. Acto seguido se sugieren los elementos que se deberían analizar para una correcta y completa reflexión respecto de la justificación del sentido de los fallos proferidos por la Corte Constitucional y la Corte Suprema de Justicia de Colombia. Por último, se aplica el modelo simple ajustado a la extensión del trabajo tomando como unidad de análisis una sentencia proferida recientemente por parte de la Sala Penal de la Corte Suprema de Justicia. En este ejercicio queda evidenciada la utilidad de la estructura argumentativa, así como los límites que comporta. En el estudio de la sentencia se observó que la Sala fundamentaba el sentido del fallo de manera principal en tres aserciones, desde las cuales se configuraron sendas estructuras argumentativas: en su análisis se encontraron deficiencias en la racionalidad de la fundamentación de dos de ellas.

1 Artículo de reflexión. 


\section{Palabras clave:}

Estructura argumentativa; racionalidad; justificación; decisión judicial; Toulmin.

\section{Abstract}

This article relates to the concept of legal argumentation, as well as its purpose. Next, the theory of Stephen Toulmin and a scheme based on his proposals, applicable to the analysis of judicial decisions. The suggestion of elements to analyze a correct and complete reflection regarding the justification of the meaning of the rulings issued by the Constitutional Court and the Supreme Court of Justice of Colombia. Finally, the simple model applies and adjusts to the extension of the work. We take the unit of analysis as a sentence recently deliver by the Criminal Chamber of the Supreme Court of Justice. In this exercise, we evidence the usefulness of the argumentative structure, as well as the limits it entails. In the study of the sentence, we observe that the Chamber based the meaning of the ruling mainly on three assertions. We configure two argumentative structures in its analysis. We find deficiencies in the rationality of the justification of two of them.

\section{Keywords:}

Argumentative structure; rationality; justification; judicial decision; Toulmin.

\section{Introducción}

Las teorías en torno a la decisión judicial racional tienen como finalidad la caracterización de los parámetros que permitan controlar las decisiones que adoptan los jueces a efectos de establecer si las mismas son fruto de la aplicación de las normas jurídicas y los precedentes pertinentes para el caso concreto, o si, por el contrario, estas son fruto de la simple actividad volitiva del juez. De esta forma se desconocen, pues, las reglas llamadas a regular el caso. Lo anterior, aclarando, de una parte, que resulta imposible aspirar a una única decisión correcta para cada caso, en tanto que, de otra, la pretensión

\footnotetext{
Cómo citar este artículo:

Mejía, A. F. (2021). El esquema argumentativo de Toulmin como herramienta de control de racionalidad de las decisiones judiciales. Revista de la Facultad de Derecho y Ciencias Políticas, 51 (134), pp. 151 -176. doi: https://doi.org/10.18566/rfdcp.v51n134.a07

Recibido: 12 de febrero de 2020

Aprobado: 05 de octubre de 2020
} 
de una decisión absolutamente racional implica la suscripción de teorías híperracionalistas que se avienen mal con la propia naturaleza del derecho, adjudicado por seres humanos que no pueden desprenderse de elementos que eventualmente pueden sesgar sus decisiones. En ese sentido, el esquema de Toulmin se presenta como una herramienta simple que permite el análisis de la decisión judicial a partir de las afirmaciones, que en el fallo se sostienen, y que fundamentan el sentido del mismo.

\section{Definición de argumentación jurídica²}

La argumentación jurídica se ha construido con base en diversos planteamientos que, en principio, no atañen de manera directa o exclusiva al ámbito del derecho. Sin embargo, en la mayoría de los casos, los teóricos usan este campo para dar cuenta de sus planteamientos: es el caso de los aportes realizados por Stephen Toulmin, Chaïm Perelman y Theodor Viehweg, quienes analizan ámbitos de la comunicación, la retórica y, en general, sobre los debates de problemas prácticos, pero cuyos aportes han sido fundamentales para la confección de una teoría más o menos estructurada de la argumentación jurídica. Las denominadas “teorías de la argumentación jurídica” se originan en obras de los años cincuenta, que se caracterizan por el alejamiento de fórmulas de lógica formal, como explicación del fenómeno del razonamiento jurídico (Atienza, 2007, p. 29)

De otro lado, se puede afirmar que la teoría más difundida y conocida, en los países de tradición romano-germánica -como Colombia- es la teoría de la argumentación jurídica, planteada por Robert Alexy. Su planteamiento se soporta en la teoría consensual de la verdad, de Jürgen Habermas. Alexy presenta el discurso jurídico como un caso especial del discurso práctico general.

Es claro que existe un espectro de discrecionalidad del que goza el juez para decidir en los casos que se someten a su juicio; sin embargo, a partir del hecho de que la jurisprudencia no puede prescindir de valoraciones, sería un error deducir que, en la medida en que estas son necesarias, hay un campo libre para las convicciones morales subjetivas del o de los aplicadores del derecho. (Alexy, 2007, p. 30).

2 Con base en Mejía. A. (p. 27). 
Por ello, el juez debe actuar sin arbitrariedad, soportando su determinación en una justificación racional. Las normas jurídicas, al ser generales, abstractas y de textura abierta no resuelven los problemas jurídicos de carácter particular. El juez, a través de la decisión jurisdiccional, llena esa laguna bajo criterios de razón práctica y "concepciones generales de justicia consolidadas en la colectividad” (Alexy, 2007, p. 44).

Por su parte, Chaïm Perelman plantea que la argumentación se soporta en acuerdos sobre las premisas y las diversas formas de vincularlas. Este acuerdo es el punto de partida a partir del cual se entrelazan los argumentos mediante técnicas usadas por el orador (Perelman, 1971, p. 39).

Stephen Toulmin, de otro lado, considera que la argumentación se refiere “a la actividad total de plantear pretensiones, ponerlas en cuestión, respaldarlas produciendo razones, criticando esas razones, refutando esas críticas, etc.” (Atienza, 2007, p. 84)

Neil McCormick, desde otra orilla, cree que "la argumentación práctica, en general, y la argumentación jurídica, en particular, cumple (...) una función de justificación” (Atienza, 2007, p. 107), en tanto que Manuel Atienza (2007) le atribuye a la teoría de la argumentación jurídica, tres funciones: "La primera es de carácter teórico o cognoscitivo, la segunda tiene una naturaleza práctica o técnica y la tercera podría calificarse como política o moral” (p. 216).

A su vez, Eveline Feteris (2007) estima que "el objetivo general de la argumentación es establecer cómo se pueden analizar y evaluar adecuadamente los argumentos" (p. 20). Tal y como sucede en otros aspectos de la vida, "con las aserciones se plantea la pretensión (claim) de que sean aceptadas. Si esta pretensión es puesta en duda, hay que, fundamentarla. Esto se realiza aduciendo hechos como razones” (Alexy, 2007, p. 96). Efectivamente; prima facie, la argumentación jurídica no procura blindar la decisión de un órgano público judicial de aspectos morales, preconceptos y prejuicios intrínsecos a la naturaleza humana. Se busca que, garantizando la efectividad del principio de publicidad y ciertas reglas que el discurso jurídico debe cumplir, se cierre en lo posible la estrecha brecha entre la arbitrariedad y la discrecionalidad. Se les otorga la posibilidad a las partes en litigio y a la sociedad en general de criticar, debatir, disentir y recurrir la decisión adoptada. En últimas, "de que sea posible una argumentación jurídica racional depende no solo el carácter científico de la jurisprudencia, sino también la legitimidad de las decisiones judiciales” (Alexy, 2007, p. 19). 
El hecho de que se otorguen justificaciones sobre los motivos para decidir en cierto sentido, no constituye per se, garantía sobre la legitimidad de lo actuado. En otros términos, justificar por sí solo aún nada dice sobre cuáles son los estándares que deben satisfacer los jueces para argumentar "racionalmente" el sentido de su decisión. Es a este respecto que la argumentación jurídica adquiere toda su relevancia. En efecto, "la justificación es la argumentación que defiende la decisión; para establecer si la argumentación es sólida es necesario conocer las normas de solidez pertinentes” (Feteris, 2007, p. 28).

En conclusión, "las teorías de la argumentación jurídica investigan las condiciones que debe satisfacer esa justificación, para que la toma de decisiones jurídicas sea racional” (Feteris, 2007, p. 32).

Teniendo en cuenta los conceptos que diversos autores tienen de la argumentación jurídica, se puede considerar a modo de conclusión que esta atañe a los presupuestos y reglas que, de manera prescriptiva, se deben cumplir para determinar si la justificación, las razones o argumentos ofrecidos por quien pretende que la decisión, ponencia o tesis sea aceptada, son racionales (Mejía, 2011, p. 32).

\section{El modelo argumentativo de Stephen Toulmin (lógica informal) $^{3}$}

A diferencia de Viehweg y Perelman, Toulmin no funda su explicación de la argumentación desde el renacimiento de la tópica o la retórica. Toulmin sigue parámetros deductivos no lógicos (al igual que Viehweg y Perelman), pero parte de una lógica no tradicional. Es decir, no teórica o ideal sino práctica, operativa 0 aplicada a la que se le puede realizar un paralelo con la jurisprudencia ${ }^{4}$ antes que con la matemática. Efectivamente: "La cuestión planteada versaba sobre la teoría lógica, mientras que el punto de partida de nuestros estudios será la práctica de la lógica” (Toulmin, 2007, p. 23).

Toulmin (2007) quiere acercar la lógica (paralela a la jurisprudencia) a la realidad cotidiana que afecta a cualquier ser humano y en la que todos los días se

\footnotetext{
Partiendo de Mejía. A. (p. 37).

Toulmin (2007) considera que, de esa manera, se "contribuye a mantener en el centro del cuadro la función crítica de la razón" (p. 25).
} 
usan argumentos. "Ciertamente el hombre de la calle (o el que no es un estudioso de la materia) espera que las conclusiones de los lógicos tengan alguna aplicación en su quehacer" (p. 18), de tal modo que, "al tratar la lógica como una suerte de jurisprudencia generalizada y al examinar las ideas confrontándolas con la práctica real de la evaluación de los argumentos y no con un ideal filosófico, podremos finalmente construir un cuadro muy diferente del tradicional” (p. 18).

Toulmin explica que un razonamiento es "la actividad central de presentar las razones a favor de una pretensión, así como para mostrar de qué manera esas razones tienen éxito en dar fuerza a la pretensión” (Atienza, 2007, p. 84) y respecto de los argumentos, realiza una diferenciación, ya que le otorga dos sentidos diferentes a ese concepto: el primero apunta a la secuencia encadenada de pretensiones y razones (tramo de razonamiento) que "establecen el contenido y la fuerza de la proposición a favor de la que argumenta un determinado hablante” (Atienza, 2007, p. 84), y el segundo, son "las interacciones humanas a través de las cuales se formulan, debaten, y/o se da vuelta a tales tramos de razonamiento”. Parece que, antes que dos sentidos diferentes para una misma palabra, Toulmin explica dos situaciones distintas. La primera, tal y como lo anuncia, da cuenta del concepto de argumento, en tanto que la segunda, apunta a las "disputas argumentativas”. La racionalidad en estas disputas proviene de la actitud del interlocutor, así, será racional quien sea abierto al argumento, reconociendo la validez de los contrarios o refutándolos igualmente con argumentos (Mejía, 2011, p. 39).

\section{La forma de los argumentos ${ }^{5}$}

\section{Tipos de argumentos}

Toulmin divide los argumentos en formales y no formales. En los formales, el eje de importancia es la estructura interna, en tanto que los argumentos no formales comportan no solo la observancia de los elementos internos, sino también los externos. Esto es, los que se efectúan en la práctica (Mejía, 2011, p. 39). Esta clasificación obedece a la misma estructura de la justificación interna y externa propuesta por Alexy. Por otro lado, Toulmin expone los tipos de falacias que se presentan en la argumentación clasificándolas según surjan de razones irrelevantes, falta de razones, razones defectuosas, suposiciones no garantizadas y de ambigüedades (Mejía, 2011, p. 39).

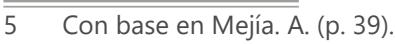


Toulmin, a diferencia de McCormick, no diferencia entre casos fáciles y difíciles, en su lógica operativa aplicada a la jurisprudencia. Esto puede sugerir que su modelo tiene carencias aplicativas respecto de los últimos, en tanto que su planteamiento no proporciona elemento alguno de juicio que permita afirmar la racionalidad o no de alguna de las plausibles interpretaciones elegidas por el órgano decisor en aquellos eventos (Mejía, 2011, p. 40).

\section{Modelo simple argumentativo de Toulmin ${ }^{6}$}

Stephen Toulmin afirma que las argumentaciones cotidianas no siguen los modelos clásicos del silogismo, sino que se soportan en la denominada "lógica operativa" que se puede estudiar desde la jurisprudencia. Así, a partir de las reglas generales de la argumentación y del discurso, devienen las particulares jurídicas. (Mejía, 2011, p. 128).

\section{Pretensión (Claim (C)):}

Es el punto de inicio del proceso argumentativo, se efectúa una aserción sobre algo, se le denomina también afirmación o conclusión (Mejía, 2011, p. 128).

\section{Razones o datos (Grounds $(G)$ ):}

Son los "hechos que podemos señalar para apoyarla [la argumentación], presentándolos como la base sobre la que descansa nuestra afirmación" (Toulmin, 2007, p. 132), si es que la afirmación efectuada es puesta en duda por algún interlocutor bajo la modalidad de $<<i$ con qué más cuentas? $>>$; sin embargo, puede que el interlocutor no pregunte por los datos o hechos que permiten realizar la afirmación inicial, sino que, por el contrario, "pida que indiquemos qué tienen que ver los datos que hemos ofrecido con la conclusión que hemos sacado" (Toulmin, 2007, p. 133), en este tipo de situación no se pregunta, ¿con qué más cuentas?, sino, ¿cómo has llegado hasta allí?, es decir, se exige justificar la manera como se dio "el paso de las razones a la pretensión” (Atienza, 2007, p. 84), y es allí donde aparecen las que Toulmin llama garantías (Mejía, 2011, p. 131).

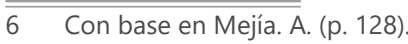




\section{Garantía (Warrant (W)):}

Las proposiciones que aquí se deben exponer no son hechos, sino reglas, principios, enunciados, etc., "que nos permitan realizar inferencias en lugar de agregar información adicional” (Toulmin, 2007, p. 134), los enunciados que se tienden de puente entre los datos o las razones y la conclusión, se caracterizan por ser de carácter general. Con un ejemplo ${ }^{7}$ se puede resumir lo hasta aquí expuesto:

Harry es súbdito británico $\rightarrow$ pretensión (C)

Harry nació en Bermuda $\rightarrow$ datos o razones (D)

Quien nace en Bermuda es súbdito británico $\rightarrow$ garantía $(\mathrm{G})$

Con el modelo:

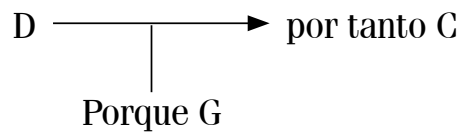

\section{Respaldo (Backing (B)):}

$\mathrm{Si}$ aun habiendo expuesto datos y garantías para sustentar cierta afirmación, "quien la ha puesto en duda no ha quedado satisfecho, porque pone en tela de juicio no solo un argumento en particular, sino la cuestión más general de la garantía” (Toulmin, 2007, p. 140), deben esgrimirse otro tipo de argumentos en los que necesariamente descansan las garantías, y "sin las cuales las propias garantías carecerían de autoridad y vigencia” (p. 140). Toulmin considera, que el tipo de respaldo ofrecido a las garantías varía de un campo de argumentación a otro. (Mejía, 2011, p. 132).

\section{Cualificadores modales (Qualifiers (Q)):}

Si las garantías no cumplen con el objetivo de que el interlocutor acepte la afirmación de manera incuestionable (usando el adverbio "necesariamente" en el argumento), se acude a un tipo de garantía que, de manera provisional, permite el paso de los datos a la conclusión; en esta clase de garantía se deben usar términos modales como "probablemente" (Mejía, 2011, p. 132).

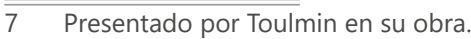


Toulmin traza un ejemplo en el que plasma su teoría:

(W) Porque una persona nacida en Bermuda será generalmente súbdito británco

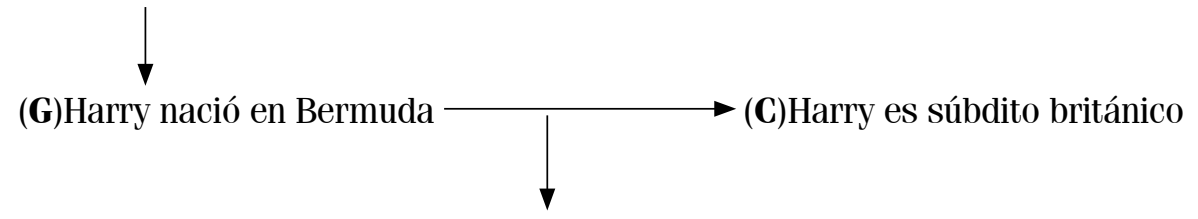

(Q)Por tanto, presuntamente

(R) a menos que sus padres sean extranjeros o haya sido naturalizado americano

Manuel Atienza (2007), por su parte, brinda un ejemplo de carácter jurídico que grafica los elementos del modelo argumentativo referido (p. 88):

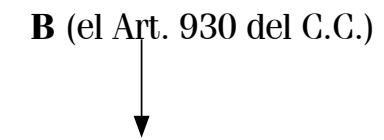

W (los hijos tienen derecho a suceder a los padres)

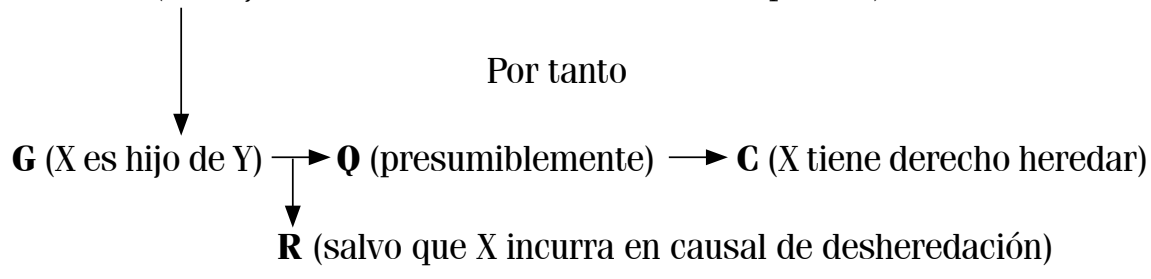

Aunque el esquema simple no ofrece más elementos, se ha decidido adicionar las justificaciones interna y externa (de la estructura argumentativa) de conformidad con la propuesta de Alexy. Lo anterior, con la finalidad de que resulte más completo el análisis de decisiones jurisdiccionales. Efectivamente, la adición garantiza un parámetro superior para determinar la racionalidad de las mismas: de una parte, desde la tradicional estructura silogística de la decisión judicial (justificación interna -argumentos formales para Toulmin -), de otra, desde la fundamentación de las premisas que se usan en la justificación interna (justificación externa). Estos aspectos se pueden resumir tal y como sigue: 
A. Estructura argumentativa interna (justificación interna):

Forma simple:

- Para la fundamentación de una decisión jurídica debe aducirse por lo menos una norma universal.

- La decisión jurídica debe seguirse lógicamente al menos de una norma universal, junto con otras proposiciones.

Forma general:

- Siempre que exista duda sobre si A es un T o un Z, hay que aducir una regla que decida la cuestión.

- Son necesarios los pasos de desarrollo que permitan formular expresiones cuya aplicación al caso en cuestión no sea ya discutible.

- Hay que articular el mayor número posible de pasos de desarrollo. (Mejía, 2011, p. 125).

B. Estructura argumentativa externa (justificación externa):

Reglas de la carga de argumentación:

- Quien pretende tratar a una persona X de modo distinto de una persona Z, está obligado a fundamentarlo.

- Quien ataca una proposición o una norma que no es objeto de la discusión debe dar una razón para ello.

- Quien ha aducido un argumento solo está obligado a dar más argumentos en caso de contraargumentos.

- Quien introduce en el discurso una afirmación o manifestación sobre sus opiniones, deseos o necesidades que no se refiera como argumento a una anterior manifestación, tiene, si se le pide, que fundamentar por qué introdujo esa afirmación o manifestación (Mejía, 2011, p. 140).

Lo realmente importante del esquema de Toulmin es que permite realizar un análisis de carácter inductivo de la decisión judicial. En la tradición jurídica europeocontinental el derecho se aplica a partir del método deductivo, extrayendo de las normas generales consecuencias jurídicas, para el caso concreto, con base en lo probado en el proceso. La estructura argumentativa de Toulmin invita a invertir la fórmula: se inicia con el sentido de la decisión escrutando la racionalidad de los argumentos en los cuales descansa. Esta cadena analítica parte de las afirmaciones que subyacen y soportan el fallo. Otra de las bondades pragmáticas del modelo es que permite identificar fácilmente la ratio decidendi, de modo tal que el análisis se centra en los elementos realmente determinantes de la decisión. 


\section{Aplicación del esquema argumentativo a decisiones jurisdiccionales}

Para una mejor estructuración del análisis de sentencias, además de los aspectos ya señalados, resulta pertinente, y dependiendo del tipo de decisión que se estudie, realizar un esquema que dé cuenta de los principales aspectos de la decisión. En ese sentido, se recomienda, sin pretensión alguna de exhaustividad, ni con ánimo prescriptivo, incluir los aspectos que se refieren a continuación y solo aplicables a las decisiones de la Corte Constitucional colombiana y la Corte Suprema de Justicia en sede de casación:

\section{Sentencias proferidas por la Corte Constitucional}

Sentencias de control de constitucionalidad abstracto: Norma(s) demandada(s), normas presuntamente vulneradas, fundamento de la presunta vulneración normativa, problema jurídico, respuesta al problema jurídico; razón o motivo por el cual se falló de esa manera (ratio decidendi), afirmaciones que soportan esta razón (claim, en el esquema de Toulmin).

Sentencias de control de constitucionalidad concreto: Derecho(s) fundamental(es) presuntamente vulnerado(s), hechos que generan la vulneración, actuación procesal relevante, problema jurídico, respuesta al problema jurídico; razón o motivo por el cual se falló de esa manera (ratio decidendi), afirmaciones que soportan esta razón (claim, en el esquema de Toulmin).

\section{Sentencias proferidas por la Corte Suprema de Justicia:}

Aspectos relevantes (hechos y actuación procesal relevante), causal de casación, vía de ataque al fallo y su fundamentación, problema jurídico, respuesta al problema jurídico; razón o motivo por el cual se falló de esa manera (ratio decidendi), afirmaciones que soportan esta razón (claim en el esquema de Toulmin).

Es oportuno aclarar que, respecto de las sentencias proferidas por la Corte Suprema de Justicia en sede de casación, el esquema argumentativo tiene limitaciones en razón de que no se retoman elementos de fondo. En realidad, el recurso extraordinario de casación tiene por objeto primigenio la salvaguarda del derecho objetivo. Ello implica que elementos importantes para la racionalidad de la decisión pueden quedar excluidos del análisis, al no actuar el tribunal de cierre de la jurisdicción ordinaria como juez de instancia. 
Por efectos pragmáticos y espaciales, solo se referirá una decisión recientemente adoptada por Sala Penal de la Corte Suprema de Justicia con la finalidad de presentar el análisis de la decisión usando la estructura argumentativa propuesta:

Sentencia SP2582-2019. Radicación 49283 de diez (10) de julio de dos mil diecinueve (2019) M.P. Patricia Salazar Cuéllar.

Hechos que originan la acción penal:

El 9 de febrero de 2013, en el interior de Billares Robin, José Luis Tordecilla Sánchez murió por disparo de Yerneis Jiménez Cañate, aprovechando que su hermano, Yeferson Jiménez Cañate, lo mantenía maniatado, asiéndolo de sus brazos, en desarrollo de una riña que se produjo en torno al juego de billar del que participaban.

\section{Actuación procesal relevante:}

Se le imputan a Yeferson Jiménez Cañate como coautor de los delitos de homicidio agravado (artículos 103 y 104 del Código Penal), uso de menores de edad para la comisión de delitos (Artículo 188 D ibídem), hurto calificado y agravado (artículos 239, 240 y 241 ibíd.) y fabricación, tráfico, porte o tenencia de armas de fuego, accesorios, partes o municiones (Artículo 365 ibíd.), en concurso de conductas punibles.

Presentado el escrito de acusación, le correspondió al Juzgado 3. ${ }^{\circ}$ Penal del Circuito con funciones de conocimiento de esa ciudad adelantar la etapa de juzgamiento, celebrándose las audiencias de acusación y preparatoria, la audiencia de juicio oral y público. Se profirió el fallo absolutorio, siendo impugnado mediante recurso de apelación por la representante de la fiscalía.

La Sala Penal del Tribunal Superior de Barranquilla, en decisión del 5 de agosto de 2016, revocó parcialmente el fallo, declarando responsable a Yeferson José Jiménez Cañate, en calidad de coautor del delito de homicidio, bajo la circunstancia de agravación punitiva consistente en haber colocado a la víctima en situación de indefensión (artículos 103 y 104-7 del Código Penal). Se le impuso la pena principal de 400 meses de prisión y las accesorias de privación del derecho a la tenencia y porte de armas por 15 años, e inhabilitación de derechos y funciones públicas por 20 años. 
Cargo en sede de casación, vía de ataque al fallo y su fundamentación se hallan en el numeral 3 del Artículo 181 de la Ley 906 de 2004, por violación indirecta de la ley, proveniente de un error de derecho por falso juicio de convicción. La condena del procesado se fundamentó en prueba de referencia.

En el juicio oral, la fiscalía empleó la declaración anterior de Elme José Guzmán Morelo (prueba de referencia), ante la imposibilidad de su localización, y la de Hermelis Cassiani Herrera (prueba de refutación), para impugnar la credibilidad de Luis David Cassiani Cassiani.

La entrevista de Hermelis Cassiani Herrera, introducida al juicio con el único fin de impugnar la credibilidad de un testigo, de acuerdo con el Artículo $\underline{403}$ de la Ley 906 de 2004, solo puede emplearse para refutar lo que el testigo ha declarado, cuyo objeto es desvalorar el testimonio impugnado y su estimación debe llevarse a cabo de acuerdo con los postulados de la sana crítica. La entrevista recibida a Cassiani Herrera solo debió ser utilizada para impugnar la credibilidad_de Luis David Cassiani Cassiani, mas no "para unirse a los indicios (...)".

De otra parte, en relación con la declaración de Elme José Guzmán Morelo, se afirma que es falso que haya sido introducida como prueba de referencia en la audiencia preparatoria, pues la misma fue autorizada en el curso del juicio oral ante la imposibilidad de la fiscalía de localizar el testigo, en tanto este suministró una dirección falsa. Agrega que la Fiscalía ni siquiera allegó elemento material probatorio alguno que demostrara la existencia de esa persona, razón por la cual no debió ser objeto de valoración.

Ninguno de los testigos presentados en juicio presenció el momento en que fue baleado el occiso y los indicios del móvil y de huida son construidos por el ad quem a partir de hechos indicadores especulativos, de allí que con la sola declaración falaz del testigo de referencia no es posible emitir fallo de condena en contra del procesado.

\section{Problema jurídico:}

¿Existe error de derecho por falso juicio de convicción en razonamiento del juez de segunda instancia al contrariar la prohibición del inciso 2 del Artículo 381 del CPP? 


\section{Resuelve:}

No casar la sentencia impugnada. Por tanto, el problema jurídico se desata de manera negativa, esto es, NO existió error de derecho por falso juicio de convicción en el razonamiento del juez de segunda instancia ya que no contraría la prohibición del inciso 2 del Artículo 381 del CPP.

La cuestión a continuación, una vez determinado la resolución del problema jurídico, se centra en establecer la o las razones que sustentan el sentido de la respuesta al problema delimitado. En este acápite, se halla la denominada razón de la decisión:

\section{Ratio decidendi:}

De una parte, la prueba de referencia valorada encuadra dentro del concepto "eventos similares" señalado en el literal b) del Artículo 438 CPP que permite, de manera excepcional, la admisibilidad de este tipo de prueba. De otro lado, la declaración de Hermelis Cassiani Herrera se incorporó a título de prueba de referencia, en calidad de prueba de refutación toda vez que el mismo había fallecido para la fecha del juicio oral y su ofrecimiento en esta etapa procesal no requiere de protocolos especiales de descubrimiento ni tiene que ser solicitada en la audiencia preparatoria. Por último, la prueba complementaria en el presente caso está conformada básicamente por los testimonios de Robin Alberto Guevara Herrera y Luis David Cassiani Cassiani, además de las construcciones inferenciales que el juez colegiado denominó indicios de móvil y de huida.

Tal y como se observa, en la razón de la decisión existen tres afirmaciones que, desde el esquema argumentativo de Toulmin, son el punto de partida a título de pretensiones (claim). Resulta pertinente aclarar que el recurso aborda otra censura del recurrente consistente en la falta de identidad entre la persona que falleció y quien participó en la riña, asunto que la Corte desestima por carecer de fundamentación. Por tanto, al respecto no se graficará estructura argumentativa alguna. A continuación, las afirmaciones que conforman la ratio:

(C1) La prueba de referencia valorada encuadra dentro del concepto "eventos similares" señalado en el literal b) del Artículo 438 CPP, que permite, de manera excepcional, la admisibilidad de este tipo de prueba.

(C2) La declaración de Hermelis Cassiani Herrera se incorporó a título de prueba de referencia, en calidad de prueba de refutación, toda vez que el 
mismo había fallecido para la fecha del juicio oral y su ofrecimiento en esta etapa procesal no requiere de protocolos especiales de descubrimiento ni tiene que ser solicitada en la audiencia preparatoria.

(C3) La prueba complementaria en el presente caso está conformada básicamente por los testimonios de Robin Alberto Guevara Herrera y Luis David Cassiani Cassiani, además de las construcciones inferenciales que el juez colegiado denominó indicios de móvil y de huida.

Como se observa, las aserciones denominadas C2 y C3 contienen, a su vez, afirmaciones que pueden ser objeto de análisis a partir del esquema argumentativo de Toulmin; es decir, respecto de la afirmación C2 se puede cuestionar el fundamento de la afirmación según la cual, "su ofrecimiento en esta etapa procesal no requiere de protocolos especiales de descubrimiento ni tiene que ser solicitada en la audiencia preparatoria" (Corte Suprema de Justicia, Sentencia SP25822019. Radicación 49283 M.P. Patricia Salazar Cuéllar), en tanto que respecto de la afirmación C3 se podría poner en tela de juicio la calidad de prueba complementaria necesaria para condenar de "las construcciones inferenciales que el juez colegiado denominó indicios de móvil y de huida", ello, al tenor de lo señalado en el inciso 2 del Artículo 381, CPP. Se ha decidido, en vez de dar lugar a la creación de afirmaciones individualmente consideradas, otorgarles un tratamiento conjunto que deberá generar hechos independientes que soporten la conclusión.

\section{Gráfico estructuras argumentativas}

\section{Estructura argumentativa 1}

(C1) La prueba de referencia valorada encuadra dentro del concepto "eventos similares" señalado en el literal b) del Artículo 438 CPP que permite, de manera excepcional, la admisibilidad de este tipo de prueba.

(G1.1) El declarante no se encontraba disponible para declarar en el juicio oral.

(G1.2) Su indisponibilidad derivaba de circunstancias especiales de fuerza mayor, racionalmente insuperables, como aquella de no ser localizado en la dirección donde supuestamente residía. La indisponibilidad devenía del hecho de que no fue ubicado en su presunto lugar de residencia, no obstante que se llevaron a cabo tareas de campo dirigidas a su consecución. 
(W1) Las circunstancias descritas encuadran en la causal excepcional de admisibilidad de la declaración anterior al juicio, a título de prueba de referencia, ya que se acredita la presencia de un evento similar_a los previstos en el literal b) del Artículo 438 de la Ley 906 de 2004.

Figura 1. Gráfico estructura argumentativa 1

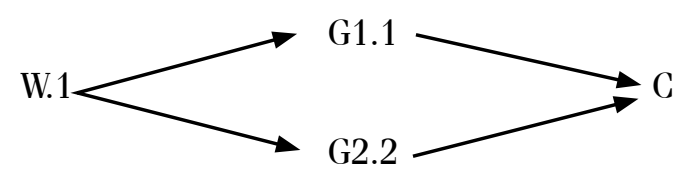

Fuente.

(C2) La declaración de Hermelis Cassiani Herrera se incorporó a título de prueba de referencia, en calidad de prueba de refutación toda vez que el mismo había fallecido para la fecha del juicio oral y su ofrecimiento en esta etapa procesal no requiere de protocolos especiales de descubrimiento ni tiene que ser solicitada en la audiencia preparatoria.

(G2) El fiscal interrogó al testigo en torno a si le había comentado lo sucedido a su padre el día de los acontecimientos, y si le había narrado que la muerte de Tordecilla Sánchez se produjo a manos de Yarney y Yefre. Admitió que le comentó a su progenitor lo sucedido en el billar, pero negó que haya involucrado al acusado. Como quiera que el deponente reveló que su padre había fallecido para ese momento del juicio, el acusador solicitó al juez que se le permitiera emplear su declaración anterior a efectos de impugnar la credibilidad del testigo.

(W2.1) La presentación de la declaración anterior de Hermelis Cassiani Herrera para impugnar la credibilidad de su hijo, Luis David Cassiani Cassiani, operó, en este caso, como una prueba de refutación al tenor del Artículo 403, CPP.

(W2.2) La presentación de la declaración anterior de Hermelis Cassiani Herrera para impugnar la credibilidad de su hijo, Luis David Cassiani Cassiani, operó, en este caso, como una prueba de referencia al tenor de los artículos 440 y 438 lit. d) del CPP. 
(W2.3) El ofrecimiento de la declaración en el juicio oral no requiere protocolos especiales de descubrimiento ni tiene que ser solicitada en la audiencia preparatoria porque la necesidad de acudir a este mecanismo surge durante el interrogatorio y está consagrada expresamente en la ley como mecanismo para ejercer los derechos de confrontación y contradicción

(B2.3) Artículo 16 CPP.

Figura 2. Gráfico estructura argumentativa 2

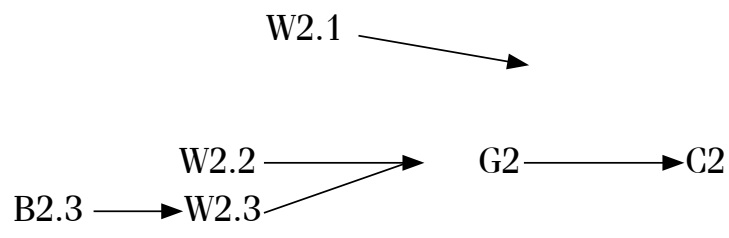

\section{Estructura argumentativa 3}

(C3) La prueba complementaria en el presente caso está conformada básicamente por los testimonios de Robin Alberto Guevara Herrera y Luis David Cassiani Cassiani, además de las construcciones inferenciales que el juez colegiado denominó indicios de móvil y de huida.

(G3.1) El testimonio de Robin Alberto da cuenta de los momentos previos a la comisión del delito, en tanto que el de Luis David Cassiani fue impugnado en su credibilidad, en virtud de la entrevista rendida por Hermelis Cassiani.

(G3.2) De los hechos se desprende la participación de Yeferson José Jiménez Cañate en el homicidio.

(W3.1) El Artículo 382 señala el testimonio como medio de conocimiento.

(W3.2.1) El indicio de móvil indica que, iniciada una discusión, posteriormente enfrentamiento violento y luego contienda a golpes, es lógico inferir que, en ese contexto, se desencadena el uso de un arma de fuego para matar a Tordecilla Sánchez. 
(W3.2.2) Conforme a las reglas de la experiencia, del hecho de salir corriendo del sitio una vez producido el suceso es posible inferir no solamente la participación criminal sino también, por ejemplo, que las personas suelen resguardarse ante el hecho del disparo y no necesariamente por haber intervenido en la conducta punible.

(Q3.2.2) No obstante, es innegable que en las inferencias que hizo el Tribunal a partir de los hechos referidos, se presentan lógicas y razonables y sus deducciones en sana crítica convergen hacia la responsabilidad penal del acusado

(B3) Se cumple con la exigencia del inciso 2 del Artículo 381. CPP.

Figura 3. Gráfico estructura argumentativa 1

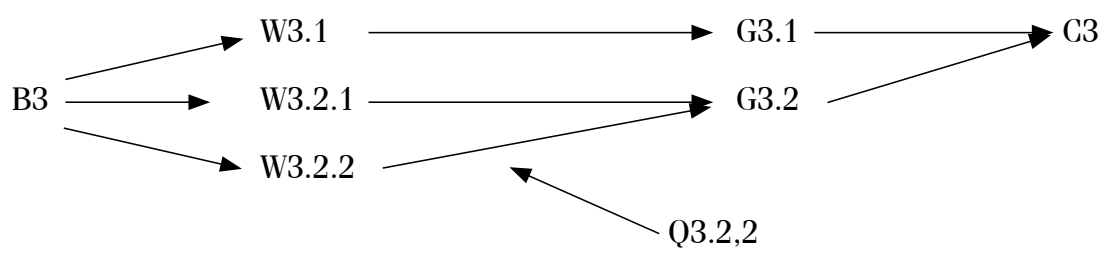

Fuente: $X X X X$

\section{Análisis de las estructuras argumentativas}

El análisis se centrará exclusivamente en las estructuras 1 y 2 elementos que ameritan ser puestos en tela de juicio.

\section{Acerca de la estructura argumentativa 1}

La Corte otorga plena validez al razonamiento de los jueces de instancia en la medida en que considera que la circunstancia que se presentó en el caso encuadra perfectamente en la previsión normativa de "o evento similar" del literal b) del Artículo 438, CPP, sin realizar mayor esfuerzo argumentativo para justificar su posición. El artículo y literal en comento señalan: 


\title{
ARtículo 438. ADMISIÓN EXCEPCIONAL DE LA PRUEBA DE REFERENCIA. Únicamente es admisible la prueba de referencia cuando el declarante: \\ b) Es víctima de un delito de secuestro, desaparición forzada o evento $\underline{\text { similar }}$
}

A su paso, el Artículo 437, CPP estipula el concepto de la prueba de referencia:

\begin{abstract}
AR'TíCULO 437. NOCIón. Se considera como prueba de referencia toda declaración realizada fuera del juicio oral y que es utilizada para probar o excluir uno o varios elementos del delito, el grado de intervención en el mismo, las circunstancias de atenuación o de agravación punitivas, la naturaleza y extensión del daño irrogado, y cualquier otro aspecto sustancial objeto del debate, cuando no sea posible practicarla en el juicio.
\end{abstract}

Se observan dos elementos fundamentales en las normas transcritas: en primera instancia, la posibilidad solamente excepcional de admitir pruebas de referencia. Evidentemente ello se debe a que, con este tipo de prueba, se rompe en alguna medida con las garantías establecidas en el Artículo 16, CPP, incluso teniendo en cuenta la salvedad señalada en el Artículo 441, CPP. En segundo término, el literal b) se refiere, de manera taxativa, a los delitos de secuestro y desaparición forzada. No obstante, adiciona una cláusula que permite incorporar diversas situaciones no contempladas de manera específica al señalar "o evento similar".

Ahora, ¿qué se puede entender por evento similar? Si se tiene en cuenta que las dos circunstancias expresamente señaladas son constitutivas de delito, se podría argüir que solo eventos que configuren reproche penal podrían tenerse en cuenta para admitir pruebas de referencia en el marco referido en el literal b). Sin embargo, también se podría argumentar que, si esa hubiere sido la finalidad prevista por el legislador , habría simplemente consagrado "o delitos similares", caso en el cual sería razonable concluir, que el concepto de "eventos similares" permite abarcar situaciones no constitutivas de delito.

Otro elemento hermenéutico que se debe tener en cuenta es la imposibilidad física de asistir al juicio, más allá de que esta dificultad constituya un ilícito. Efectivamente, quien se encuentra secuestrado o ha sido desaparecido forzosamente, no puede asistir al juicio, pero esta situación ha sido causada por un tercero y existe imposibilidad de resistir por parte del testigo. 
En estricto sentido se podría, entonces, afirmar que solo podría entenderse por "evento similar" aquel que 1) constituya delito, y 2) que comporte la imposibilidad física de acudir al juicio. No obstante, siendo menos riguroso en el paralelismo fáctico, podría eliminarse el elemento delictual, reduciendo, por tanto, estos eventos a aquellos en los que el deponente tenga una imposibilidad física de asistir generada por una circunstancia que le ha sido impuesta por un tercero. En ese sentido, la situación del caso fallado por la Corte no se subsumiría en la cláusula final del literal b) del Artículo 438.

¿Podría decirse que el hecho de que la Fiscalía no localizó al testigo en el lugar en el que manifestó residir, y que, además, agotó las tareas de campo dirigidas a su consecución configura una circunstancia que puede encuadrar en el supuesto normativo? ¿Esta circunstancia podría ser calificada como racionalmente insuperable? ¿Ello podría ser tildado de circunstancia especial de fuerza mayor? Parece difícil responder afirmativamente a los cuestionamientos elevados a partir de argumentos racionales aceptables. No obstante, es la vía por la que opta la Corte.

En realidad, equiparar la falta de hallazgo de una persona con circunstancias constitutivas de delitos como secuestro o desaparición forzada parece desatinado, esto, sin tener en cuenta que la Fiscalía cuenta con los recursos para lograr la comparecencia de un testigo al juicio, y, que, por tanto, se le debe exigir más que el simple esfuerzo por hallar a alguien. No se puede perder de vista que, lo que se encuentra en juego, es la libertad de una persona, y no puede existir laxitud en materia de estándar de prueba en cuanto a la determinación con grado de certeza de la ocurrencia de determinado hecho configurativo de delito. Por demás, no solo aparenta ser desatinado el acercamiento hermenéutico de la Corte sino también peligroso: nótese que el concepto "evento similar" lo llena con la noción de "no encontrarse disponible" (en G1.1) y este claramente comprendería casos que distarían diametralmente de aquellos contemplados de manera concreta en el literal b). En otros términos, en este caso, a la Fiscalía le bastó con señalar que no había hallado a un testigo a pesar de haberlo buscado. Si ello configura el "no encontrarse disponible", ¿respecto de un testigo que se esconde o huye podría brindársele tratamiento de prueba de referencia a su declaración previa, toda vez que él "no se encuentra disponible" para declarar en el juicio?

En últimas, pareciera que la Corte no logra, con su argumentación, persuadir al auditorio. Entre dos decisiones soportadas en sendas opciones interpretativas, esto es: 1. Considerar la declaración como prueba de 
referencia por encuadrarse en el supuesto normativo de "eventos similares"; o 2. No admitir como prueba de referencia la declaración, ya que no se halla cobijada bajo el concepto "eventos similares", la segunda requiere no solo de menor argumentación, sino que la primera requeriría un estándar superior de justificación al brindado por la Corte. Tal y como se señaló al inicio del análisis, la prueba de referencia solo procede de manera excepcional, de suerte que, para darle ese tratamiento a situaciones no contempladas de manera taxativa en la disposición se deben exigir argumentos de tal entidad que no permitan fisuras racionales como las analizadas.

\section{Acerca de la estructura argumentativa 3}

La afirmación con la que inicia el esquema argumentativo se dirige a justificar la existencia de pruebas adicionales a la de referencia, a efectos de sostener la inexistencia en la violación de la prohibición del inciso del Artículo 381 CPP. En primera instancia, la Corte señala la existencia del testimonio de Luis Cassiani, que acompañaría a la prueba de referencia, y que daría vigorosidad al sentido condenatorio del fallo.

Al respecto se puede afirmar que es reprochable que la Corte afirme que esta prueba cimienta un conocimiento más allá de toda duda, teniendo en cuenta que el testimonio se hallaba originariamente dirigido a constatar la ausencia de responsabilidad del acusado. Es evidente que la relevancia que le otorga la Corte no es al testimonio per sé, sino a la refutación de que fue objeto este y referida en la estructura argumentativa 2. Afirmar que el testimonio es soporte de la condena y acompaña la prueba de referencia, cuando ello en últimas riñe con la realidad, resulta, cuando menos, falaz.

En segunda instancia, ya que el testimonio de Robin Guevara da cuenta de circunstancias previas a la comisión del delito, de él no se desprende la responsabilidad del finalmente condenado. Por ello, la presunción de inocencia se mantiene incólume; sin embargo, del relato de los hechos sí se puede inferir, de manera lógica y probabilística, la consiguiente comisión de un delito por parte de quienes discutían.

En tercer término, la fortaleza de los indicios se antoja débil. Respecto del indicio denominado de móvil (el más robusto de ellos), la Corte considera que las reglas de la experiencia indican que, iniciada una discusión, seguida de enfrentamiento violento y luego contienda a golpes, lo que a continuación se presenta es el uso de un arma de fuego. Si bien, mal podría calificarse el 
análisis de falaz, y siendo, por el contrario, plausible; no es menos cierto que no siempre, de una contienda a golpes, se sigue el uso de armas de fuego. Ya que la fortaleza del indicio descansa en la racionalidad de la inferencia lógica que se realiza, en el caso concreto e indicio es débil.

En cuanto al indicio de huida, este, en definitiva, carece de cualquier asidero racional si el análisis se efectúa bajo el prisma del in dubio pro reo; en efecto, la misma Corte concede que: "Si la conclusión a la que se puede llegar a partir del hecho indicador no es única sino una entre múltiples posibilidades, la gravedad del indicio aumenta o decrece conforme a sus contingentes circunstancias".

Conforme a las reglas de la experiencia es muy probable comprender que, de la contienda, se siguió el disparo, mas del hecho de salir corriendo del sitio una vez producido el suceso es posible inferir no solamente la participación criminal sino también, por ejemplo, como lo plantearon los intervinientes en la audiencia de sustentación, que las personas suelen resguardarse ante el hecho del disparo y no necesariamente por haber intervenido en la conducta punible.

Entonces, si son múltiples las posibilidades a partir del hecho indicador, ¿por qué darle mayor relevancia o credibilidad a la que señala la responsabilidad penal? ¿No comporta precisamente lo contrario la garantía universal de presunción de inocencia?

De los aspectos socializados pareciera que, en realidad, sí se configura un falso juicio de convicción al concedérsele a los medios de prueba un valor que la ley no le asigna. Ello, por cuanto la prueba con mayor peso en realidad es la de referencia (dudosamente incorporada y valorada como tal). Adicionalmente, las pruebas que la acompañan (testimonios de Robin y Luis, de refutación y los dos indicios) mal podrían ser consideradas como reveladoras de responsabilidad penal del endilgado.

\section{Estructura argumentativa interna (justificación interna) ${ }^{8}$ :}

Las estructuras argumentativas son lógicas de conformidad con lo observado, ya que cumplen con las reglas tanto de las formas simples como

8 Con base en Mejía. A. (p. 55). 
las generales de argumentos de conformidad con la teoría de Alexy ${ }^{9}$ (Mejía, 2011, p. 55).

\section{Estructura argumentativa externa (justificación externa) ${ }^{10}$ :}

Aunque solo se examinaron las estructuras argumentativas 1 y 3, durante el análisis se evidenció que la estructura argumentativa 2 goza de racionalidad. En otros términos, que las premisas de esta pueden ser justificadas racionalmente. En lo que concierne a la estructura argumentativa 1, se notó que se le dio tratamiento de prueba de referencia a una circunstancia que no encuadra dentro de los elementos exceptivos dispuestos en el literal b) del Artículo 438, CPP, viciando, por tanto, el paso a la pretensión (C1) a partir de los elementos que la sustentan (G1.1 y G1.2) y (W1). Respecto de la estructura argumentativa 3 se concluyó que, el testimonio de Luis Cassiani (G3.1), en calidad de indicador de la responsabilidad del condenado, resultaba falaz; en tanto que el de Robin (G3.1) no da cuenta de la responsabilidad de Yeferson al referirse solo a circunstancias anteriores a la comisión del delito. Por otra parte, los indicios (W3.2.1 y W.3.2.2) carecen de la virtualidad para desprender de ellos responsabilidad penal. Así las cosas, en esta estructura tampoco se encuentra justificado el paso de las premisas a la conclusión. En últimas, la ratio se soporta en afirmaciones a las que se arriba de manera equivocada 0 acudiendo a falacias argumentativas.

\footnotetext{
9 Forma simple:

(J.2.1) Para la fundamentación de una decisión jurídica debe aducirse por lo menos una norma universal.

(J.2.2) La decisión jurídica debe seguirse lógicamente al menos de una norma universal, junto con otras proposiciones.

Forma general:

(J.2.3) Siempre que exista duda sobre si $A$ es un $T$ o un $Z$, hay que aducir una regla que decida la cuestión.

(J.2.4) Son necesarios los pasos de desarrollo que permitan formular expresiones cuya aplicación al caso en cuestión no sea ya discutible.

(J.2.5) Hay que articular el mayor número posible de pasos de desarrollo (Mejía, 2011, p. 56).

10 Partiendo de Mejía. A (p. 56).
} 
Por último, los argumentos del tribunal cumplieron parcialmente con las reglas de la carga de argumentación de Alexy ${ }^{11}$. En ese ámbito se puede afirmar que la regla 3.1. no fue cumplida, ya que la Corte se aparta de la jurisprudencia por ella establecida. En lo tocante con la regla 3.3, la Corte no ofrece argumentos adicionales a los dispensados por las instancias respecto del tratamiento de prueba de referencia por ser constitutiva de "evento similar", así como tampoco agrega argumentos para el fortalecimiento y valoración de los indicios.

\section{Conclusiones}

1. La argumentación jurídica da cuenta de los elementos, presupuestos y reglas que, de manera prescriptiva, se exponen por las diferentes teorías para determinar, con algún grado de certeza, si la justificación, las razones o argumentos esbozados por quien pretende que la decisión, ponencia o tesis sea aceptada son racionales (Mejía, 2011, p. 248).

2. El modelo de Toulmin se aparta de la lógica formal deductiva. Aunque no proporciona elemento alguno de juicio que permita afirmar la racionalidad o no de alguna de las interpretaciones elegidas por el órgano decisor ante una norma que permite más de una válida, confecciona un modelo simple que puede ser perfectamente aplicado a las decisiones judiciales (Mejía, 2011, p. 248).

3. Se propone el esquema simple de Toulmin para evaluar decisiones jurisdiccionales, al que se le agregan aspectos de la propuesta de Alexy: la justificación interna (forma simple y forma general) y externa (reglas de la carga de la argumentación).

4. El esquema propuesto permite, a partir del uso del método inductivo, dar cuenta de las afirmaciones contenidas en la razón de la decisión que soporta el sentido del fallo. A su vez, permite evidenciar los hechos y reglas de carácter general que sustentan estas afirmaciones.

11 (3.1.) Quien pretende tratar a una persona $X$ de modo distinto de una persona $Z$, está obligado a fundamentarlo.

(3.2.) Quien ataca una proposición o una norma que no es objeto de la discusión debe dar una razón para ello.

(3.3.) Quien ha aducido un argumento solo está obligado a dar más argumentos en caso de contraargumentos.

(3.4.) Quien introduce en el discurso una afirmación o manifestación sobre sus opiniones, deseos o necesidades que no se refiera como argumento a una anterior manifestación, tiene, si se le pide, que fundamentar por qué introdujo esa afirmación o manifestación. 
5. Como toda herramienta que tenga como pretensión evaluar la racionalidad de una decisión jurisdiccional, tiene limitaciones. No solo referente a la exclusión de evaluación de elementos sicológicos, sociológicos, ideológicos, de estado de ánimo, entre otros, inherentes a la naturaleza del ser humano, sino también aquellos propios de la ambigüedad del lenguaje, característica de la cual goza el derecho.

6. Se analizó una decisión proferida por la Corte Suprema de Justicia en la que se evidenciaron problemas argumentativos en las estructuras 1 y 3. En la primera, principalmente, respecto de la fundamentación racional de lo que, en el caso concreto, se consideró que encuadraba en el presupuesto normativo "o evento similar" en el contexto del literal b) del Artículo 438, CPP. En el análisis de la estructura argumentativa 3 se determinó que el testimonio de Luis Cassiani no puede ser validado como la prueba que acompaña a la de referencia, por cuanto este daba cuenta de la no responsabilidad del condenado como hecho reprochado en el ámbito penal. Afirmación similar se puede predicar del testimonio de Robin Alberto, quien tampoco da cuenta de la responsabilidad penal del endilgado. Finalmente, el indicio de huida cuenta con poca fortaleza en razón de las diversas inferencias lógicas que se pueden construir y a las conclusiones a las que se puede arribar a partir del hecho indicador. Por su parte, el indicio denominado móvil (el más fuerte de los dos) puede ser atacado en la medida que las reglas de la experiencia indican que es plausible que iniciada una discusión, seguida de enfrentamiento violento y luego contienda a golpes, lo que a continuación se presenta es el uso de un arma de fuego, no obstante, no siempre de una contienda a golpes se sigue el uso de armas de fuego.

\section{Referencias}

Alexy, R. (2007). Teoría de la argumentación jurídica (Atienza M. \& Espejo, I., Trad.). Madrid: Centro de Estudios Políticos y Constitucionales.

Atienza, M. (2007). Las razones del derecho, teoría de la argumentación jurídica. Mexico: Universidad Nacional Autónoma de México.

Corte Suprema de Justicia. (2019 10 de julio). Sentencia SP2582-2019 (M.P. Patricia Salazar Cuéllar). Recuperado de: http://consultajurisprudencial.ramajudicial.gov. co:8080/WebRelatoria/csj/index.xhtml

Feteris, E. (2007). Fundamentos de la argumentación jurídica, revisión de las teorías sobre la justificación de las decisiones judiciales (Supelano, A., Trad.). Bogotá: Editorial Universidad Externado de Colombia.

García, J.A. (1998). Teorías de la tópica jurídica. Madrid: Civitas. 
Manassero, M. de L. (2005). La nueva retórica como razonamiento práctico. La teoría de la argumentación de Chaïm Perelman. Granada: Editorial Comares.

Manassero, M. de L. (1994). La nueva retórica de Chaïm Perelman y la tradición aristotélica. Cádiz: Servicio de publicaciones Universidad de Cádiz.

Mejía. A. (2011). Estructuras argumentativas empleadas en la decisión sobre la admisión de la prueba ilícita (análisis a partir de las sentencias de la Corte Suprema de Justicia y la Corte Constitucional colombiana, desde la entrada en vigencia de la ley 906 de 2004). (Tesis para la maestría en DerechoProcesal). Universidad de Medellín.

Perelman, C. (1971). Traité de l'argumentation. Ciudad: Editorial.

Perelman, C. (2004). Retórica y argumentación. Bogotá: Editorial Norma.

Perelman, C. (2007). Los usos de la argumentación. Ciudad: Editorial Península.

Perelman, C. (2007). Tópica y jurisprudencia (Díez Picazo, Trad.).. Ciudad: Editorial Tirant lo Blanch.Toulmin, S. (1979). El puesto de la razón en la ética. Alianza: 1979.

Viehweg, T. (1964). Tópica y jurisprudencia (trad. De Díez Picazo, L. de la $2^{\mathrm{a}}$ ed. Alemana; prólogo de García de Enterría, G.). Madrid: Taurus.

Viehweg, T. (2007). Tópica y jurisprudencia (Díez Picazo, Trad.). Madrid: Editorial Tirant lo Blanch. 